\title{
Effects of silymarin fractions on pro-inflammatory cytokine secretion from macrophage and colonic epithelial cell lines
}

\begin{abstract}
Silymarin is an extract of milk thistle seeds, consisting of four major classes of flavonoligans: silybinin, silychristin, silydianin and isosilyibinin. These compounds are known for their anti-oxidant and anti-inflammatory properties. The goal of this study was to determine if different fractions of the crude extract of silymarin inhibited pro-inflammatory cytokine secretion from macrophage and colonic epithelial cell lines
\end{abstract}

Methods: Milk thistle seeds were obtained from a commercial supplier. The powdered seeds $(30 \mathrm{~g})$ were percolated with methanol $(100 \mathrm{~mL}$ x 3$)$. Evaporation of the solvent at reduced pressure yielded a residue. The residue was then chromatographed on a flash chromatography system. Fractions were monitored by TLC on silica gel, as described previously, and confirmed by (LC/MS) analyses. The crude silymarin extract and six distinct fractions were tested in two different cell culture systems. The secretion of TNF- $\alpha$ was determined from LPS-stimulated RAW 264.7 murine macrophages. We also characterized the effects of silymarin fractions on TNF-a induced chemokine (IL8) secretion, using a HT-29 colonic epithelial cell line

Results: Fraction 5 (containing mainly silybinin and silychristin) was most potent for inhibiting TNF- $\alpha$ secretion from LPS-stimulated macrophages (IC50=47.7 $\mu \mathrm{g}$ / $\mathrm{ml}$ ). Fractions 2 and 4 (composed of mostly silybinin A and B) exhibited IC50 values of $\approx 65 \mu \mathrm{g} / \mathrm{ml}$ in this assay. In contrast, the crude silymarin extract (IC50 value of $88.5 \mu \mathrm{g} / \mathrm{ml}$ ) was less potent for inhibiting TNF- $\alpha$ secretion. The potency order of tested fractions, for inhibiting IL-8 secretion by HT-29 cells was: Fraction 2 (IC50=19.9 $\mu \mathrm{g}$ ) $\mathrm{ml})>$ Fraction $5(\mathrm{IC} 50=32.8 \mu \mathrm{g} / \mathrm{ml})>$ Crude extract $(36.1 \mu \mathrm{g} / \mathrm{ml})$.

Summary: Silybinin and isosilybinin containing fractions of silymarin more potently inhibited pro-inflammatory cytokine secretion from macrophage and colonic epithelial cell lines.

Conclusion: These data contribute to the characterization of optimal anti-inflammatory flavonoligans, which can be used for follow-up testing in animal models of colitis

Keywords: silymarin, natural products, macrophages, ht-29 cells
Volume 5 Issue 4 - 2017

\section{George Talbott, Tibebe Woldemariam, Leo R Fitzpatrick \\ Department of Pharmaceutical and Biomedical Sciences,} California North State University, USA

\begin{abstract}
Correspondence: George Talbott, California North State University, College of Pharmacy, USA, Tel 91668674I3, Email gtalbott@cnsu.edu
\end{abstract}

Received: July II, 2017 | Published: August 29, 2017
Abbreviations: LPS, lip polysaccharides; IBD, inflammatory bowel disease; TNF- $\alpha$, tumour necrosis factor; RP-HPLC, reverse-phase high performance liquid chromatography; TLC, thin layer chromatography

\section{Introduction}

Silymarin is an extract of milk thistle seeds. The principal components of silymarin are silibinin A, silibinin $\mathrm{B}$, isosilibin $\mathrm{A}$, isosilibin B, silichristin A, silichristin B and silidianin. Silibinin is generally considered to be the major and most active component in silymarin. ${ }^{1}$ The first six compounds exist as equimolar mixtures as trans-diastereoisomers. These diastereomers have very similar $1 \mathrm{H}$ and 13C NMR spectra and have no characteristic signals for facile identification of the individual isomers. ${ }^{2}$ These compounds are known for their anti-oxidant and anti-inflammatory properties. ${ }^{3}$ Human clinical trials have investigated milk thistle or silymarin primarily in individuals with hepatitis or cirrhosis, although small studies have been reported about individuals with acute lymphoblastic leukemia, prostate cancer, breast cancer, and hepatocellular carcinoma. ${ }^{4}$ Of note, silymarin showed positive results in a small clinical trial utilizing patients with Ulcerative Colitis. ${ }^{5}$ In an attempt to discover novel bioactive plant natural products for the potential treatment of inflammatory bowel disease (IBD), we examined Silymarin fractions that could have significant potential for containing an anti-colitis agent. Therefore, the anti-inflammatory effects of these fractions isolated from silymarin were tested for blocking cytokine production induced by lip polysaccharide (LPS) on macrophages and tumour necrosis factor (TNF- $\alpha$ ) on colonic epithelial cells. These cell types and cytokines are thought to play an important role in animal models of colitis and IBD. ${ }^{6-8}$

\section{Materials and methods}

\section{Plant material}

The seeds of Milk thistle, used in this investigation were obtained from a commercial supplier (San Francisco Herb Co., San Francisco, CA, USA). 


\section{Reagents and reference materials}

The analytical reference standard for silibinin was purchased from Sigma. All solvents and reagents were of annular grade.

\section{Extraction and isolation}

The powdered seeds $(30 \mathrm{~g})$ were percolated with methanol $(100 \mathrm{mLx} 3)$. Evaporation of the solvent at reduced pressure yielded a residue. The residue was chromatographed on a CombiFlash Companion ${ }^{\circledR}$ flash chromatography system (Teledyne Isco) (gradient, water/MEOH, $0,100 \%$, v/v) on RediSep Rf Gold C18Aq, 12g, at a flow rate of $30 \mathrm{ml} / \mathrm{min}$. Fractions $(15 \mathrm{ml}$ each) were monitored by TLC on silica gel using dichloromethane -hexane - acetone (10:5:1, v/v/v) as the mobile phase.

\section{Experimental chemistry methods}

Mass spectra were recorded on Agilent 1200 Series LC/MSD VL system. MS data were recorded on Agilent Technology (HP) instrument with 5973 Network Mass Selective Detector (MS model). All the fractions and eluates were monitored by thin layer chromatography (TLC) using precoated silica gel 60 F254, $0.25 \mathrm{~mm}$ aluminum backed plates (Merck). The TLC spots were detected by spraying with vanillin- $\mathrm{H}_{2} \mathrm{SO}_{4}$ reagent followed by heating. All chemicals and reagents used for TLC were of analytical grade. All the fractions and eluates were monitored by reverse-phase system on LaChrom Elite ${ }^{\circledR}$ HPLC System.

\section{Thin layer chromatography analysis}

Flavonolignans were analyzed by Thin Layer Chromatography (TLC). Chloroform-acetone-formic acid $(75: 16.5: 8.5)$ was used as a solvent system. Silymarin is characterized under UV-365nm by two intense green-blue fluorescent zones of silybin/isosilybin $(\mathrm{Rf}=0.6)$, silychristin $(\mathrm{Rf}=0.35)$.

\section{Reverse-phase high-performance liquid chromatogra- phy (RP-HPLC) analysis}

A Reverse-Phase High-Performance Liquid Chromatography (RP-HPLC) method was developed using water: methanol, gradient 100:0 to $0: 100 \%$ over 20 minutes for separation of the compounds. The RP-HPLC LaChrom Elite ${ }^{\circledR}$ Hitachi System is equipped with a photodiode-array detector (L-2455).

The crude silymarin extract and distinct fractions were tested in different cell culture systems, as described below.

\section{Murine macrophage (RAW 264.7) cell line}

One hour prior to stimulation of murine derived macrophages, silymarin fractions were added to the cell culture system at concentrations of 20 to $200 \mu \mathrm{g} / \mathrm{ml}$. RAW 264.7 murine macrophages were then stimulated with LPS $(1 \mu \mathrm{g} / \mathrm{ml})$. After 4hours, supernatant was collected for the determination of TNF- $\alpha$, using an appropriate ELISA kit from R\&D Systems Inc. (Minneapolis, MN). Cell viability was determined by the trypan blue exclusion method.

\section{Colonic epithelial (HT-29) cell line}

One hour prior to stimulation of human colonic epithelial cells, silymarin fractions were added to the cell culture system at concentrations of 20 to $100 \mu \mathrm{g} / \mathrm{ml}$. HT-29 colonocytes were then stimulated with TNF- $\alpha(10 \mathrm{ng} / \mathrm{ml})$. After 4 hours, supernatant was collected for the determination of IL-8, using an appropriate ELISA kit from R\&D Systems. Cell viability was assessed by the trypan blue exclusion method.

\section{Statistical analysis}

Non-linear regression analyses were done with a GraphPad Prism ${ }^{\circledR}$ software program (Carlsbad, CA), in order to determine the reported IC50 values.

\section{Results}

\section{Chemistry data}

Figure 1 demonstrates the extraction and isolation procedure for isolation of sylimarins from finely powdered Milk Thistle seeds.

\section{Spectral data of isolated compounds}

In the course of our bioassay-guided screening of compounds, a two-step fractionation afforded active compounds identified as silibinin, isosilibinin, and silychristin from the seeds of Milk thistle as confirmed by MS, TLC, HPLC, and by comparison with literature data. The purity and identity of the compounds was also examined by diode array detection and by comparison with standards using the Hitachi system. The structures of these compounds are summarized in Figure $2 \& 3$. The physiochemical properties of the silymarins are shown in Table 1. The spectroscopic data of silymarin fractions are shown in Table 2.

Table I Physiochemical properties of the silymarins

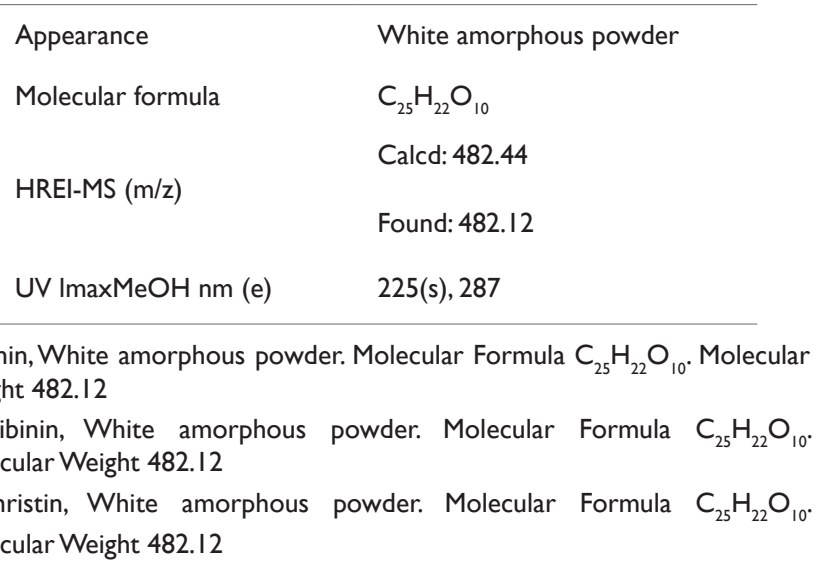

\section{Biology data}

As shown in Figure 4, fraction 5 (containing mainly silibinin) was most potent for inhibiting TNF- $\alpha$ secretion from LPS-stimulated macrophages (IC50 value $=47.7 \mu \mathrm{g} / \mathrm{ml}$ ). Fractions 2 and 4 (composed of mostly isosilibin, and silibinin) had IC50 values of $\approx 65 \mu \mathrm{g} / \mathrm{ml}$ in this assay. In contrast, the crude silybinin extract (IC50 value $=88.5 \mu \mathrm{g}$ / $\mathrm{ml}$ ) was least potent for inhibiting TNF- $\alpha$ secretion. The potency data for TNF- $\alpha$ inhibition by the various silymarin fractions is summarized in Table 3.

Cell viability was determined by trypan blue exclusion and no significant differences in viability were found for any of the fractions tested in Raw 264.7 cells or HT-29 cells except for Fraction 4 which significantly reduced cell viability at $100 \mathrm{ug} / \mathrm{ml}$ and $200 \mathrm{ug} / \mathrm{ml}$ in HT29 cells (data not shown).Based on the data in the macrophage cell line, only certain silymarin fractions were utilized for follow-up biological testing. As shown in Figure 5, both the crude extract (left panel) and fraction 5 (right panel) effectively inhibited IL-8 secretion from the colonic epithelial cell line. For inhibiting IL-8 secretion by HT-29 cells, the potency order (IC50 values) for tested fractions was: Fraction $2(19.9 \mu \mathrm{g} / \mathrm{ml})>$ Fraction $5(32.8 \mu \mathrm{g} / \mathrm{ml})>$ Crude Extract $(36.1 \mu \mathrm{g} / \mathrm{ml})$. These results are summarized in Table 4 . 


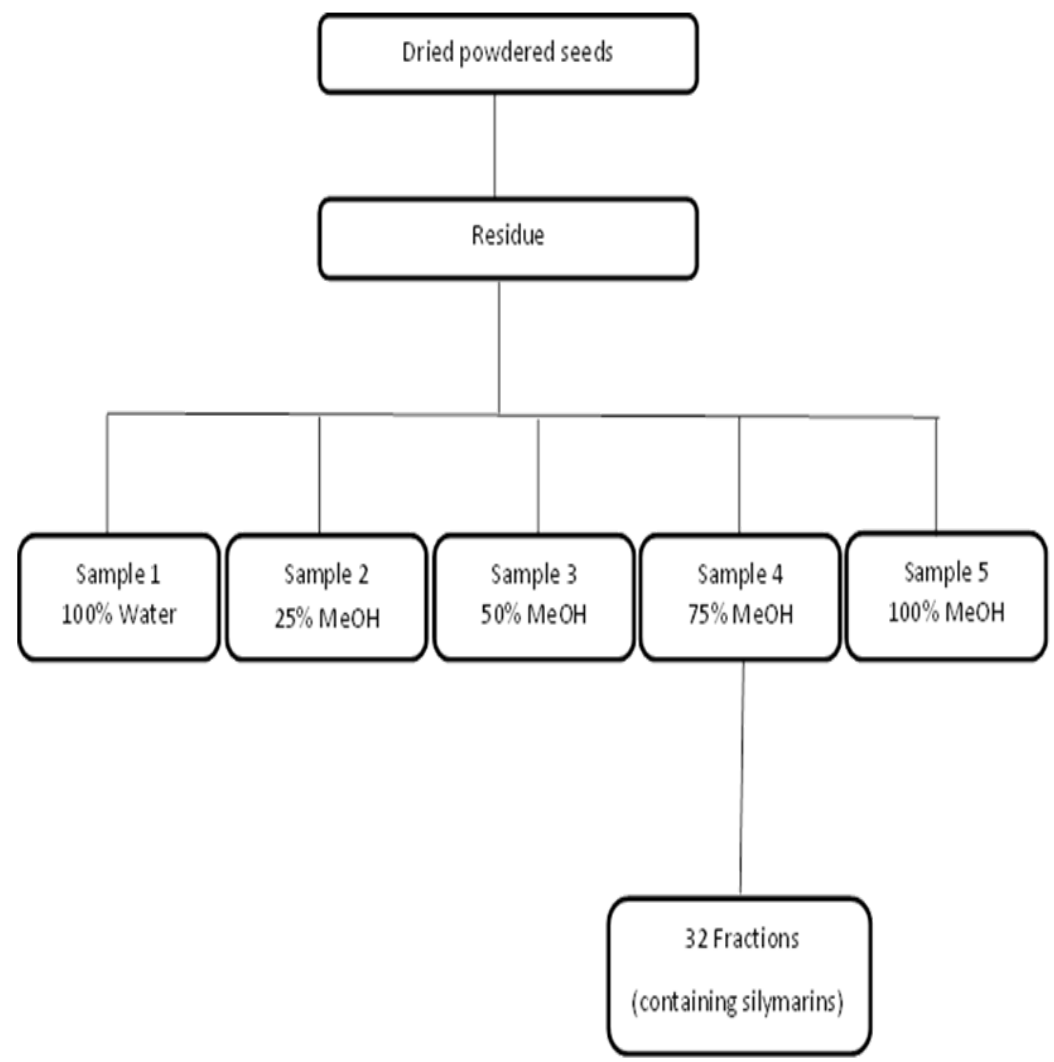

Figure I Extraction and isolation procedure.

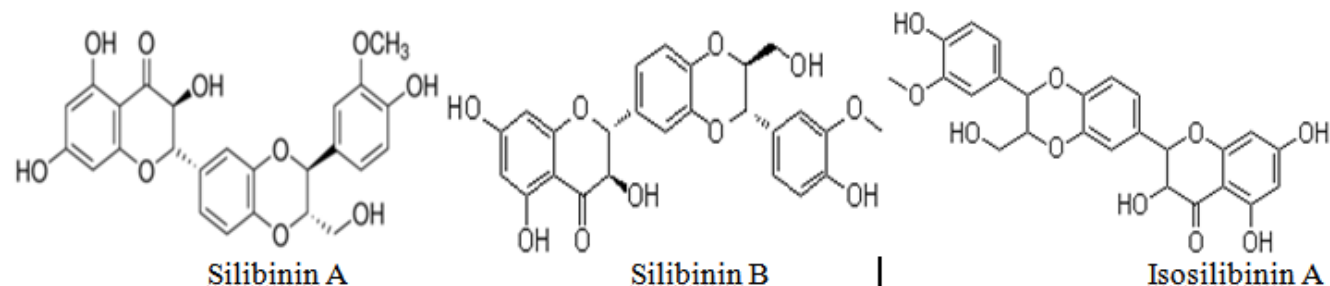

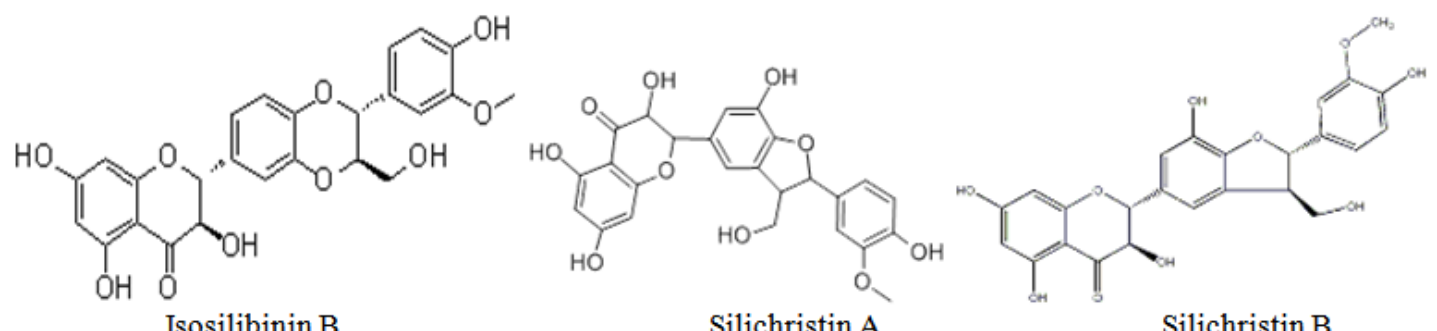

Isosilibinin B

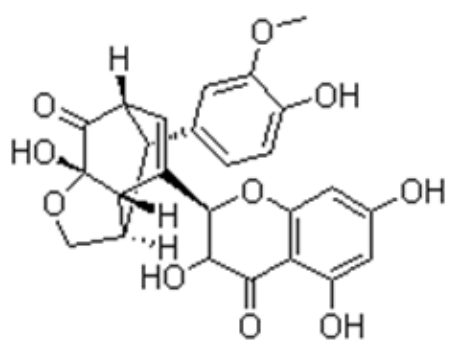

Silidianin

Figure 2 
A

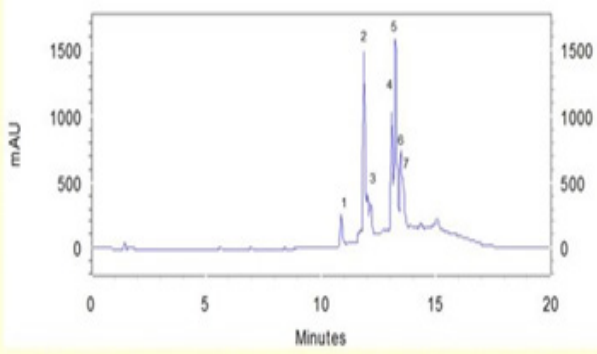

RP.HPLC Chromatographic profle of Milk Thistle Seed Crude Methanol Extract (Peaks 1:Taxifolin, 2: Sillichristin, 3: Aplgenin 7-olucoside, 4: Sillibinin A, 5: Sillbinin B, 6: Isosibinin A, 7: isosilibinin B

C

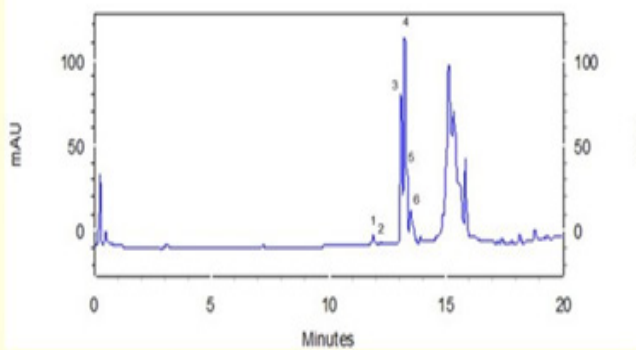

RP.HPLC Chromatographic profle of Milk Thistle Fraction 5 (Peaks: 1: Silichristin, 2: Apigenin 7-olucoside, 3: Sillbinin A, 4: Sillbinin B, 5: (sosibinin A, 6: Isos ibinin B)
B

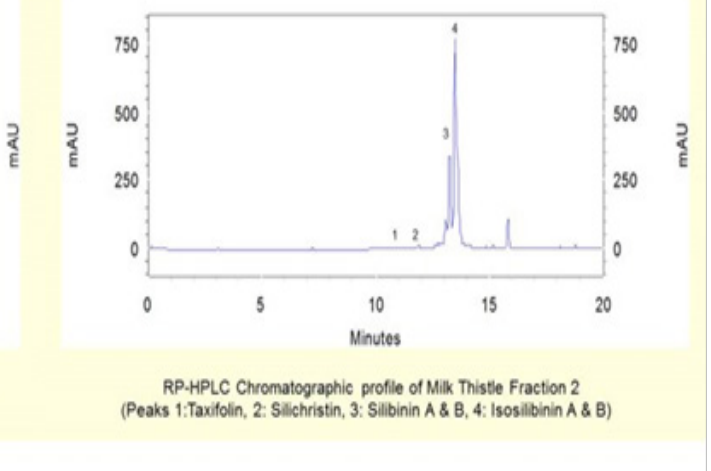

Figure 3: The HPLC identifications of the crude extract $(A)$ and key silymarin fractions $2(\mathrm{~B})$ and $5(\mathrm{C})$ are shown in figure 3.

Figure 3 HPLC results.
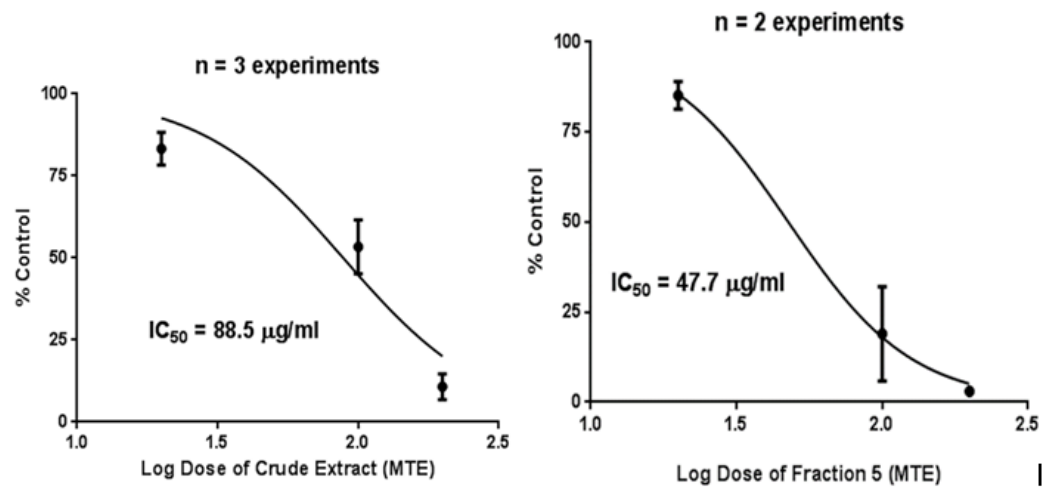

Figure 4 Raw 264.7 (macrophage) cell line representative traces.
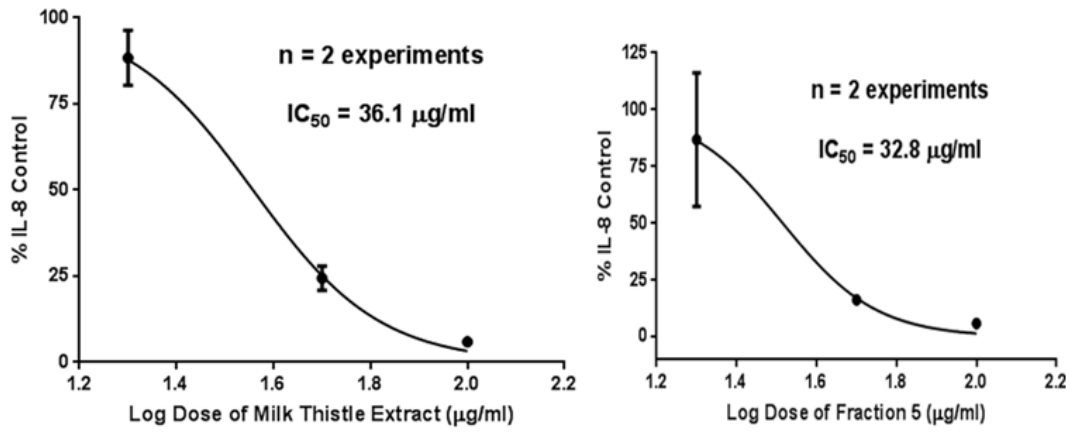

Figure 5 HT-29 (colonic epithelial cell) representative traces. 
Table 2 Spectroscopic data of silymarin fractions

\begin{tabular}{ll}
\hline Fraction & Compound(s) \\
\hline $\begin{array}{l}\text { Crude } \\
\text { Extract }\end{array}$ & $\begin{array}{l}\text { Silibinin A \& B, Silychristin, Taxifolin, Isosilibinin A \& B, } \\
\text { Apigenin }\end{array}$ \\
Fraction I & Silibinin A \& B, Silychristin \\
Fraction 2 & $\begin{array}{l}\text { Isosilibinin A \& B (major, I:3 ratio), Silibinin A \& B ( I:3 } \\
\text { ratio), Silychristin (minor), Taxifolin }\end{array}$ \\
Fraction 3 & $\begin{array}{l}\text { Taxifolin, Silychristin } \\
\text { Fraction 4 }\end{array}$ \\
Fraction 5 & $\begin{array}{l}\text { Silibinin A \& B, Taxifolin, Silychristin A \& B (major I:I ratio), Silychristin (minor), } \\
\text { Isosilibinin A \& B (minor, I:4 ratio), Apigenin }\end{array}$ \\
Fraction 6 & Silibinin A \& B, Silychristin \\
\hline
\end{tabular}

Table 3 Raw 264.7 (macrophage) cell line results summary

\begin{tabular}{ll}
\hline Fraction & IC $_{50}$ value $(\mu \mathrm{g} / \mathrm{ml})$ \\
\hline Crude & 88.5 \\
Fraction I & 109.8 \\
Fraction2 & 67.6 \\
Fraction 3 & 86.5 \\
Fraction 4 & 63 \\
Fraction 5 & 47.7 \\
Fraction 6 & 195.3 \\
Silibinin & 79.5 \\
Isosilibinin & $>200$ \\
\hline
\end{tabular}

Table 4 HT-29 (colonic epithelial cell) results summary

\begin{tabular}{ll}
\hline Fraction & $\mathbf{I C}_{50}$ value $(\boldsymbol{\mu g} / \mathrm{ml})$ \\
\hline Crude & 36.1 \\
Fraction 2 & 19.9 \\
Fraction 5 & 32.8 \\
\hline
\end{tabular}

\section{Discussion}

Our results show that crude silymarin extract, isosilibinin and silibinin containing fractions of silymarin extract inhibited proinflammatory cytokine/chemokine secretion from two different cell lines, albeit with different potencies. The cell lines were picked to represent cell types likely involved in the pathogenesis of human IBD ${ }^{8-10}$ Of potential relevance to our study, previous investigators reported that silibinin treatment $(50-200 \mu \mathrm{M}$ range) inhibited TNF $\alpha$ induced NF- $\mathrm{\kappa B}$ activation in HT29 cells. ${ }^{11}$ This mechanism of action could be the basis for the observed block of IL-8 secretion from this colonic epithelial cell line by silymarin derived fractions. Of note, all of the previous experimental IBD work with silymarin (or silibinin) was conducted with a trinitrobenzene sulfonic acid [TNBS] model of colitis. This is a model of human Crohn's Disease, ${ }^{12,13}$ while the initial clinical results were obtained in patients with Ulcerative Colitis. ${ }^{5-13}$ Ongoing work in our laboratory is examining the effects of silymarin derived fractions on cytokine production from colonic strips of mice with DSS colitis (a model of Ulcerative Colitis), utilizing an ex vivo system. $^{10-14}$

\section{Conclusion}

In summary, the in vitro results from two cell lines further suggest that silymarin, or derived fractions may prove to be an effective natural product supplement, as part of the overall therapeutic approach for the treatment of IBD. Indeed pre-clinical and clinical evidence from previous studies support this possibility. ${ }^{3-18}$ Future studies, should concentrate on which specific silymarin component(s) are most effective in other relevant pre-clinical models of IBD. ${ }^{10}$

\section{Acknowledgements}

None.

\section{Conflict of interest}

Author declares that there is no conflict of interest.

\section{References}

1. Kim S, Choi JH, Lim HI, et al. Silibinin prevents TPA-induced MMP9 expression and VEGF secretion by inactivation of the Raf/MEK/ ERK pathway in MCF-7 human breast cancer cells. Phytomedicine. 2009;16(6-7):573-580.

2. Lee DYW, Liu Y. Molecular structure and stereochemistry of silybin A, silybin B, isosilybin A, and isosilybin B, isolated from Silybum marianum (Milk thistle). J Nat Prod. 2003;66(9):1171-1174.

3. Zhu HJ, Brinda BJ, Chavin KD, et al. An assessment of pharmacokinetics and antioxidant activity of free silymarin flavonoligans in health volunteers: a dose escalation study. Drug Metab Dispos. 2013;41(9):1469-1475.

4. Scambia G, De Vincenzo R, Ranelletti FO, et al. Antiproliferative effect of silybin on gynaecological malignancies: synergism with cisplatin and doxorubicin. Eur J Cancer. 1996;32A(5):877-882.

5. Rastegarpanah M, Malekzadeh R, Vahedi H, et al. A randomized, double blinded placebo-controlled clinical trial of silymarin in ulcerative colitis. Chin J Integr Med. 2012;21(12):902-906.

6. Fitzpatrick LR, Small J, Hoerr RA, et al. In vitro and in vivo effects of the probiotic Escherichia coli Strain M-17: Immunomodulation and attenuation of murine colitis. Br J Nutr. 2008;100(3):530-541.

7. Maines LW, Fitzpatrick LR, French KJ, et al. Suppression of ulcerative colitis in mice by orally-available inhibitors of sphingosine kinase. Dig Dis Sci. 2008;53(4):997-1012.

8. Fitzpatrick LR, Wang J, Le T. In vitro and in vivo effects of gliotoxin, a fungal metabolitie: Efficcay against dextran sodium sulfate induced colitis in rats. Dig Dis Sci. 2000;45(12):2327-2336.

9. Fitzpatrick LR, Wang T, Le T. Caffeic acid phenethyl ester, an inhibitor of nuclear factor-kappaB, attenuates bacterial peptidoglycan polysaccharide-induced colitis in rats. $J$ Pharmacol Exp Ther. 2001;299(3):915-920.

10. Fitzpatrick LR, Talbott G, Woldemariam T. Effects of Silymarin Fractions on Pro-Inflammatory Cytokine Secretion from Macrophage and Colonic Epithelial Cell Lines. Gastroenterology. 2016;150(4 Suppl 1):S376-S377.

11. Raina K, Agarwal C, Agarwal R. Effect of silibinin in human colorectal cancer cells: targeting the activation of NF- $\mathrm{KB}$ signaling. Mol Carcinog. 2013;52(3):195-206. 
12. Maines LW, Fitzpatrick LR, Green CL, et al. Efficacy of a novel sphimgosine kinase inhibitor in experimental crohn's disease. Inflammopharmacology. 2010;18(2):73-85.

13. Antoniou E, Margonis GA, Angelou A, et al. The TNBS-induced colitis animal model: An overview. Ann Med Surg (Lond). 2016;11:9-15.

14. Fitzpatrick LR, Stonesifer E, Small JS, et al. The synthetic triterpenoid (CDDO-Im) inhibits STAT3, as wll as IL-17, and improves DSS-Induced Colitis in Mice. Inflammopharmacology. 2014;22(6):341-349.

15. Al-Drees A, Khalil MS. Histological and immunohistochemical effects of L-arginine and silymarin on TNBS-induced inflammatory bowel disease in rats. Histol Histopathol. 2016;31(11):1259-1270.
16. Miroliaee AE, Esmaily H, Vaziri-Bami A, et al. Amelioration of experimental colitis by a novel nanoslenium-silymarin mixture. Toxicol Mech Methods. 2011;21(3):200-208.

17. Esmaily H, Vaziri-Bami A, Miroliaee AE, et al. The correlation between NF-кB inhibition and disease activity by coadministration of silibinin and ursodeoxycholic acid in experimental colitis. Fundam Clin Pharmacol. 2011;25(6):723-733.

18. Cruz T, Galvez J, Crespo E, et al. Effects of silymarin on the acute stage of the trinitrobenzenesulphonic acid model of rat colitis. Planta Med. 2001;67(1):94-96. 